\title{
The Information Support of Virtual Research Teams by Means of Cloud Managers
}

\author{
Antoniy Rzheuskiy, Nataliia Veretennikova, Nataliia Kunanets \\ Information Systems and Networks Department, Lviv Polytechnic National University, UKRAINE, Lviv \\ E-mail: antonii.v.rzheuskyi@lpnu.ua, nataver19@gmail.com,nek.lviv@gmail.com \\ Vasyl Kut \\ Information Technologies and Analysts Department, Carpathian University named after Augustine \\ Voloshin, UKRAINE, Uzhhorod \\ E-mail: kut.vasilij81@gmail.com
}

Received: 26 June 2017; Accepted: 15 September 2017; Published: 08 February 2018

\begin{abstract}
The article deals with the creation of virtual research teams of scientists from various geographically distributed organizations united for joint interdisciplinary researches. Library social institutions are the satellites of virtual research teams and have to implement information and communication support of scientific researches. The use of cloud managers by academic libraries is proposed as platforms to facilitate remote collaborative work of the participants of the virtual research teams. The research of number of free cloud managers and their capabilities was held. The most successful cloud manager for supporting the scientific work of virtual research teams was selected by using hierarchy analysis method.
\end{abstract}

Index Terms - Scientific library, virtual research teams, cloud manager, cloud storage, remote service, benchmarking method, hierarchy analysis method, method of expert estimation, method of pairwise comparisons, alternative weight.

\section{INTRODUCTION}

Modern libraries in Ukraine have a difficult stage, which is characterized by limited resources and access opportunities to information and services. It encourages them to change traditional approaches to information service of users. The list of information services provided by libraries along with the implementation of new social communication means, platforms, formats and devices has to be changed.

Transformations of the library in order to capture the entire space of information flows, where it is located as an information institution and provides services, first of all concern the technologies of processing of electronic information presented in the global network. Libraries are becoming hybrid, interactive and open to the inevitable changes in service modes and principles of service support.

An innovative model for storing, processing and distributing data is cloud storages. In accordance with the development of these technologies, the model of the library is changing and is being rethought and it implements them and actively uses the information and library support and communication connections. Along with this, there is a tendency to join groups with people from different geographically distributed organizations for joint multidisciplinary scientific research. Libraries as information and communication centers become the ideal platform for establishing such scientific communications, opening the infrastructure of their information resources in a virtual environment using cloud technologies.

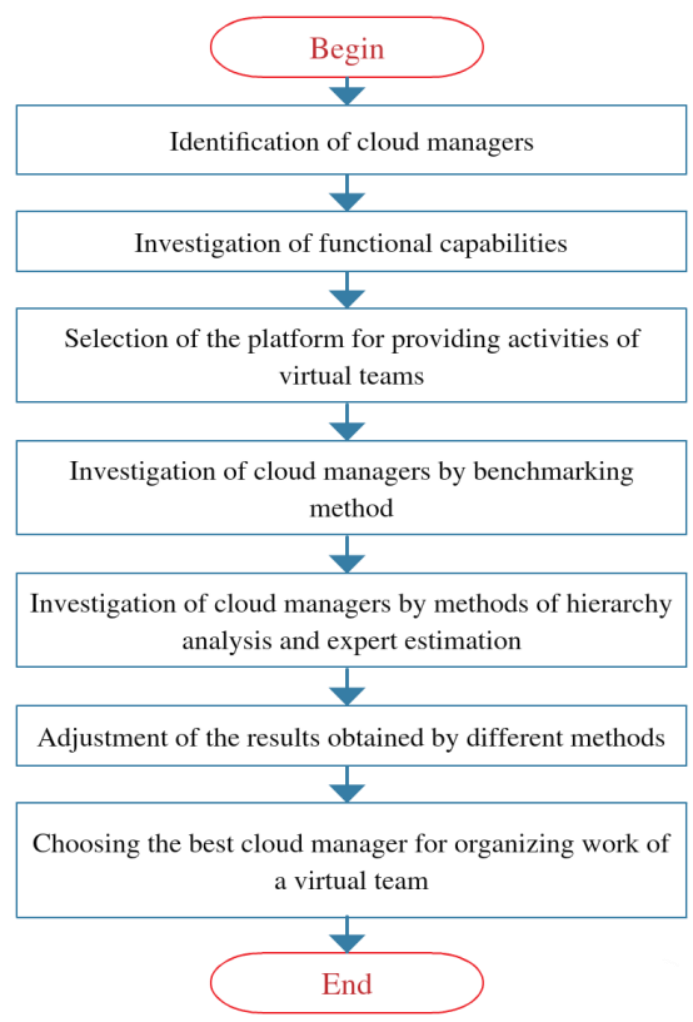

Fig.1. The algorithm for conducting this scientific research

Nowadays, there are a variety of cloud services, but there are no approaches to identify effective means of 
managing them. In this direction the article is built (Fig. 1). 1. The essence of virtual scientific teams and the factors of their creation are investigated. 2 . The key issue is the organization of information and technical support for the research activities of virtual teams. An innovative tool for establishing scientific communications in the middle of a virtual scientific team between geographically distributed participants is a cloud platform. 3. Using the benchmarking method, the functional of cloud managers is analyzed. The hierarchy analysis method is also used for the study of cloud managers; the authors use a scale of expert assessments, or grades of importance - estimates for pair comparisons in assessing the benefits of one cloud platform over another. An expert assessment procedure is conducted to identify key platform functions. In the hierarchy analysis method, a scale of expert estimates is used for pair comparisons in assessing the benefits of the first service over the second one. The application of these techniques enables to test the research results and choose the correct version of the cloud platform to ensure the scientific activity of virtual teams.

\section{RELATED WORKS}

The questions of formation of virtual research teams were considered by Camarinha-Matos L. M. [1], Chesbrough H. W. [2], Petersen S. A. [3]. Important suggestions are in the works of $\mathrm{M}$. Zhurovsky and A.Petrenko [4] who think it is necessary to create a distributed computing environment for information and technological support of dynamic virtual organizations.

Virtual technology and library management, that base their information resource in the "clouds", were studied by Sangeeta N. Dhamdhere [5]. Nandkishor Gosavi, Seetal S. Shinde and Bhagyashree Dhakulkar [6] consider the cloud storages as service-oriented systems that consist of various discrete services. V. Suresh Kumar and M. Aramudhan [7] note that users of cloud services, who are convinced of their flexibility, are exploring the opportunities for efficient and cost-effective implementation of projects such as e-commerce, highly efficient computing, social networking and web applications. Ala Arman highlights two important benefits of using cloud technologies: the lack of end-user involvement in the configuration and maintenance of cloud services; the form of prepaid services implies that the end-user pays only for the resources that are in need [8].

P. Sasikala [9] focuses on the concept of cloud services from the perspective of a variety of technologies, services and available models of the «cloud» in the government, enterprises, higher educational institutions, libraries. The use of cloud storages by libraries for saving their own data was considered in [10].

Libraries are undergoing a difficult stage, which has limited information resources, various sources of information, the need to expand the range of information services, the widespread use of electronic communications. Librarians are reviewing their role in the modern information society and mastering new skills in informational work.

\section{THE PURPOSE AND OBJECTIVES OF THE RESEARCH}

The purpose of this paper is to define the means of library and information support of scientific researches, conducted by geographically distributed research teams. It caused the forming of the following tasks:

- to establish a system for information support of virtual creative teams with free Web services;

- to determine the best cloud managers for information support of scientific work with the use of hierarchy analysis method.

\section{THE RESUlts OF ClOUd MANAGER STUdies FOR INFORMATION SUPPORT OF VIRTUAL CREATIVE TEAMS}

The library activity from information support of scientific research is gradually moving to a virtual environment. The American librarians distinguish three levels of virtuality in libraries [2]:

Level 1: The electronic access to information resources. It occurs at the first stage of library automation.

Level 2: The online access to document metadata and electronic delivery of digital copies. These technologies are gradually developing in almost all libraries.

Level 3: The remote access to electronic collections containing the full text of documents. The application of these technologies in the libraries is under development.

The implementation of these levels in library activities requires improving their work and developing skills how to use the information and communication technologies. Libraries create a remote service for library users, software and technological systems that implement the technology of remote service based on the use of information technologies for collection, preparation, storage, processing, and information presentation according to user requests. A significant part of the modern users of academic libraries who do research or business, are integrated into virtual teams. Directions of activity in virtual teams can be very diverse: manufacturing, marketing, distribution, research and development.

In this article, we will consider the peculiarities of information support of a virtual creative team, involved in the research work. The virtual creative team is a group of people from various geographically distributed organizations, united for a joint interdisciplinary research. The use of this technology ensures the collaboration of scientists from different countries to achieve this goal without the physical movement to one population centre. However, the sustainable definition of a "virtual team", even after durable discussions, has not been developed. Several interpretations of this concept close in meaning are given in scientific works $[2 ; 1]$ : 
1) The virtual team is a temporary combination of independent representatives from various institutions that based on the use of information and communication technologies are joined to carry out research. They are integrated vertically to merge the core competences of individual team members and act as a single organizational unit.

2) The virtual team is an identified group of people or organizations, which on the basis of wide use of information and communication technologies are combined for business or scientific collaboration.

A virtual team mostly creates a virtual organization. The virtual organization is an organization that is constantly developing, rapidly redefines the directions of its work for achieving practical purposes of a specific work, combining geographically remote coworkers [1].

Such scientific groups may combine geographically or institutionally distributed researchers, representatives of various fields of knowledge that provide a comprehensive systematic study of a problem. As the international experience shows, the research efficiency is significantly enhanced by the establishment of cooperation between members of the research team, which includes representatives from various cities and institutions, experts in various fields of science.

The librarians have to understand the specificity of the information needs of virtual teams and change the technology of their work to improve effective information support. The virtual teams as regular library users, in many cases, can act as information content creators. The role of librarian in the process of information service of users as members of the virtual research teams, changes to an advisor, an instructor and a mediator in obtaining the necessary information. The virtual research team is an innovative form of organization of scientific work that requires the formation of information environment for effective resource management using modern information technologies and implementation of information support of scientific researches [11]. The librarian becomes an active participant of a virtual creative team, helping to create a comfortable information environment.

Information service of a virtual team is based on the appropriate architectural and technical decisions that contribute to the relevant constant support of scientific researches.

Among the key factors to create virtual teams are:

1. Egalitarian approach to management.

2. Subjects participating in the work of virtual organization are independent in the presence of formal relationships, defined by some predetermined procedures or cooperation agreement.

3. The emphasis on a human factor, not on technology.

4. The determination of range of questions due to competencies of participants in a virtual team.

5. The difference of legislation for virtual organizations which includes teams from different countries.

6. The obligation of each member of a virtual team facilitates to achieve the goal.

7. The transparency and clarity of changes in the work or structure of a team, accepting them on the basis of discussion and with consent of all participants of a virtual team should be made.

R. Bultje and J. Wijk distinguished a number of characteristics of virtual teams that can be projected on the activity of virtual research teams [12]:

- The combination of key competencies of the virtual team members. This approach leads to synergies and ensures more effectively to achieve the goal. The professionalism of each member is essential, which leads to improvement of the organization work at whole.

- The independence of virtual teams. The community of virtual teams forms a virtual organization for performing a certain task or solving a specific problem. Each virtual team solves its tasks.

- The uniqueness of the virtual teams. The virtual team has certain uniqueness related to the originality of each member.

- The use of information technology. The importance for activities of a virtual team is to use the latest advances in the field of information and communication technologies.

- The absence of hierarchical subordination. It is achieved through equality of participants and it increases the effectiveness and efficiency of work.

- A small number of members in virtual teams. Only small virtual teams or a part of large virtual organizations can establish a clear collaboration and achieve target goals.

- Free borders. The absence of need to cross the border allows establishing effective cooperation between the members of a virtual team.

- The common intellectual property. All results obtained during the research belong to all members of a virtual team on a parity basis.

- Distributed access to information resources. Each member of a virtual team controls information resources and has an access to a common database.

- Geographical dispersion. The geographical dispersion of team members doesn't prevent the joint research using information technology and it helps to have constant communication.

- Trust. The success of the common work depends on each member of the virtual team.

Despite all the advantages of a virtual team, during the research there may be some obstacles, especially communication and information barriers (Fig. 2).

The cloud managers will become the innovative facilities for libraries to overcome the spatial and information barriers. Taking into account the realities of library for the information service of virtual creative teams, the main emphasis is on free of charge services. During the research, the following cloud managers were identified and their comparative analysis is conducted: 
1. Mover is an on-line cloud manager. It is designed exclusively for file exchange between cloud services and it does not involve creating of common space and joint access to documents.

The algorithm of sharing files between cloud storages consists of the following steps (Fig. 3):

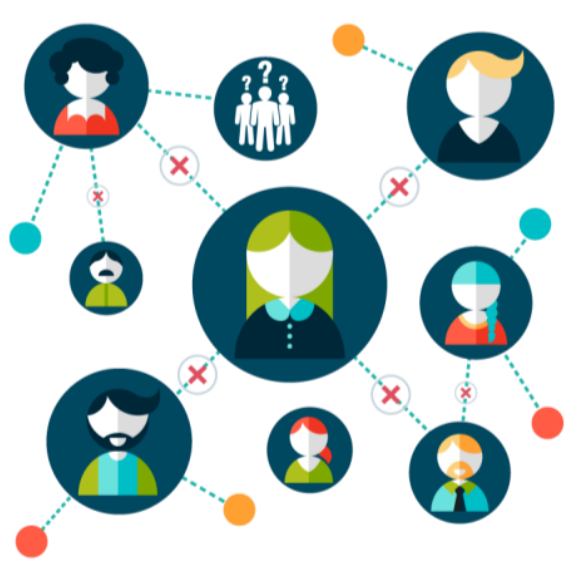

Fig.2. Communication barriers

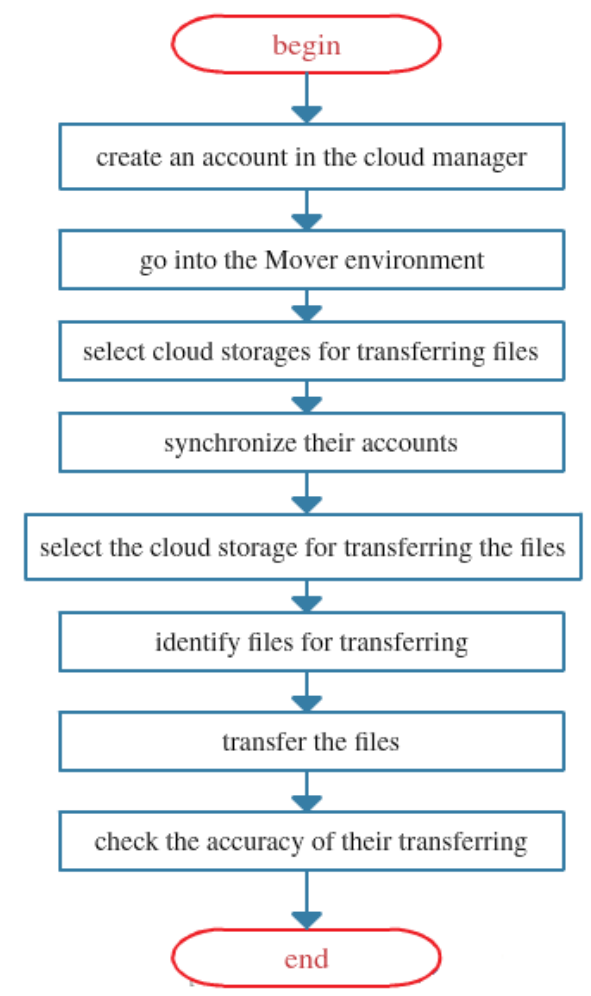

Fig.3. The algorithm of document exchange using Mover cloud manager

Mover Web-service provides an interaction with the following free cloud storages (Fig. 4):

2. Disk space of a cloud manager Multcloud reaches 10 terabytes and can store documents sent from a computer and transfer them to any other cloud storages. Multcloud functional capabilities provide file sharing via email and social networks: Twitter, Google+, Tumblr,
Facebook, and LinkedIn. However, the service has a number of disadvantages. It does not provide viewing of multimedia files, file grouping by categories, presenting them in a directory. Multcloud manager allows the exchange between 12 free cloud storages (Fig. 5).

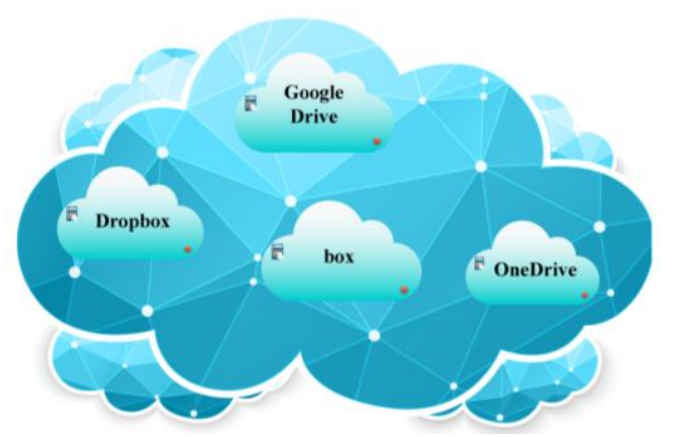

Fig.4. The document exchange between cloud storages in the Mover environment

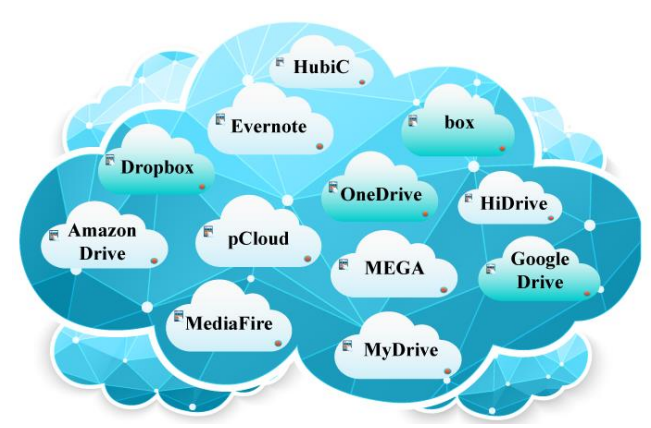

Fig.5. The integration of cloud storages in Multcloud manager

The process of file exchange is quite simple and there is the following algorithm (Fig. 6):

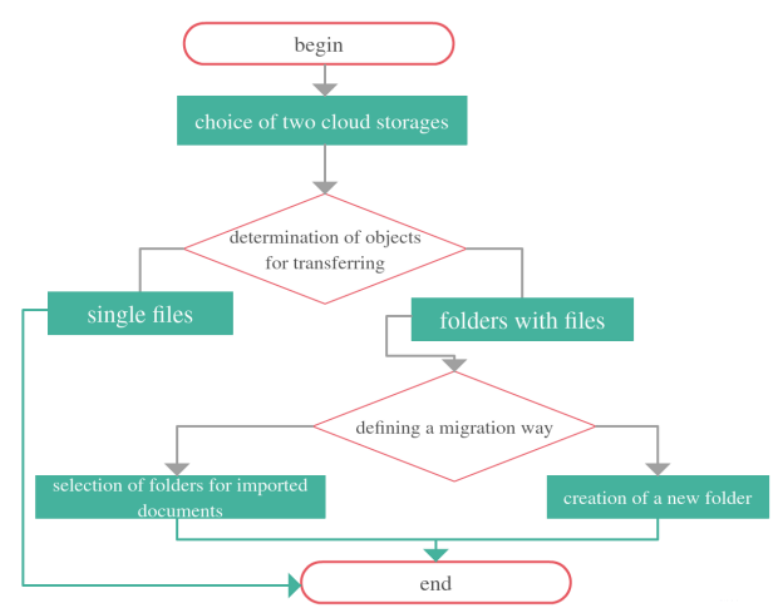

Fig.6. The algorithm of document exchange between cloud services in the Multcloud environment

3. The Web-service CloudFuze operates for a fee, but allows a test access. CloudFuze provides easy file search, dividing them into categories:

- documents,

- images,

- audio files,

- video files.

I.J. Intelligent Systems and Applications, 2018, 2, 37-46 
Moreover, it is possible the file transferring between categories. The service functionality is enhanced with the ability of file search in the general directory. CloudFuze environment allows viewing files of any type, except video. CloudFuze provides the file sharing without uploading to the cloud manager.

This cloud manager consolidates 6 cloud storages (Fig.7):

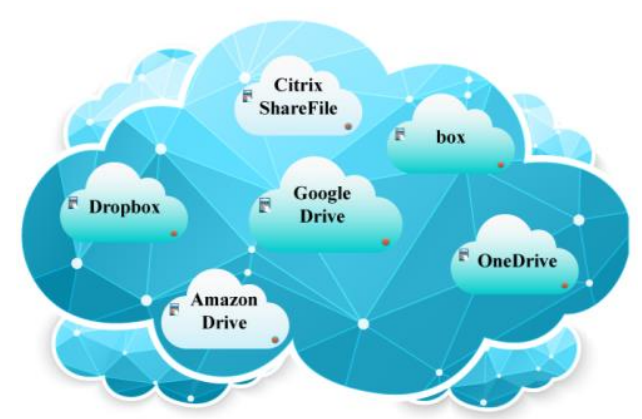

Fig.7. The list of cloud storages in the environment of CloudFuze

The functionality allows doing control of a total disc space as well as distributed one by cloud storages. The Web-service provides the file access for team work. The algorithm of file exchange between cloud storages integrated in CloudFuze is the following (Fig. 8):

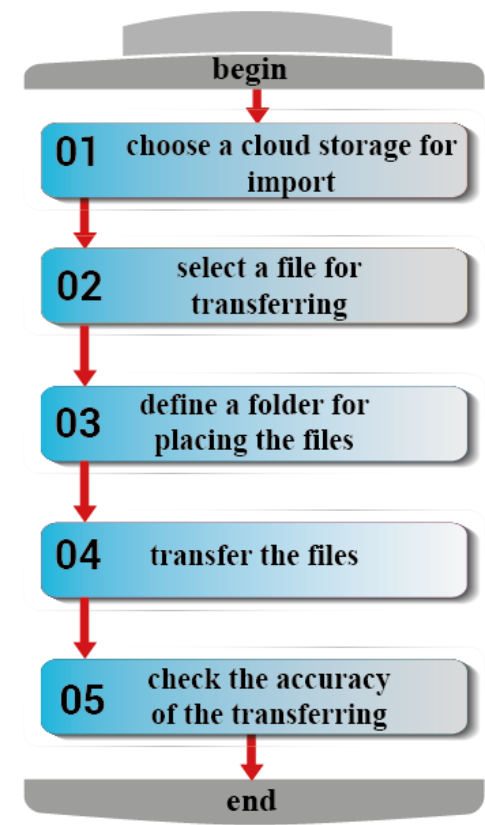

Fig.8. The process of transferring the documents in CloudFuze manager

One of the advantages of the service is an ability to view the history of file moving from the beginning of the account creation.

4. Web-service ZeroPC is designed to integrate Webapplications in one convenient shell. ZeroPC service integrates with accounts in postal services, social networks, and cloud storages. Free disk space of ZeroPC has only $1 \mathrm{~GB}$ without connecting with cloud storages. ZeroPC provides the file exchange between 7 free of charge cloud storages (Fig. 9) and 4 social networks: Facebook, Twitter, Instagram, Flickr.

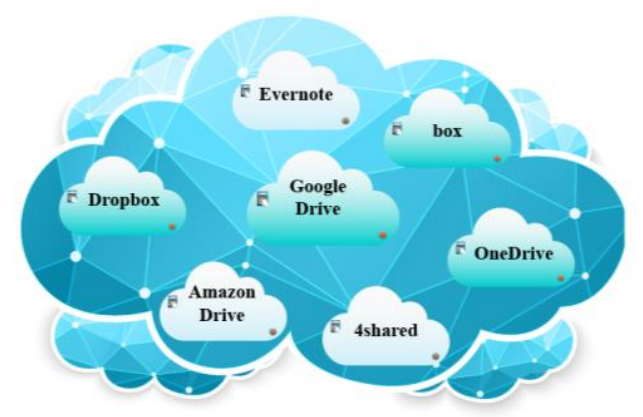

Fig.9. The integration of cloud storages in ZeroPC environment

However, due to the fact that the developers reported the ZeroPC platform will be shut down soon, we remove this cloud Manager from consideration because it has no future prospects.

5. CloudHQ is a cloud manager, such as Mover, ensures file exchange between different cloud storages. It has an ability to integrate 7 free cloud storages (Fig. 10) and 6 mail apps (Gmail, Office 365Mail, Outlook.com, FastMail, YahooMail, iCloudMail).

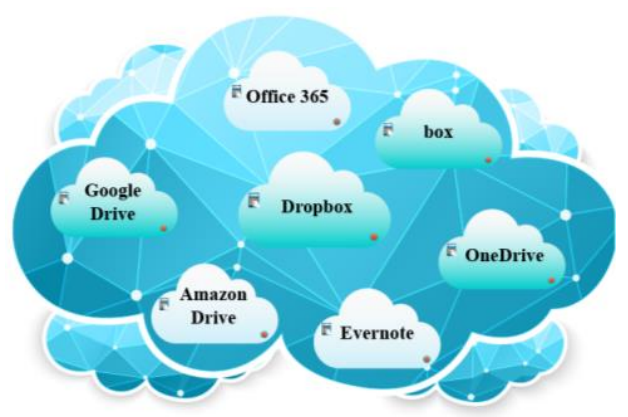

Fig.10. Cloud storages for file exchange in CloudHQ environment

A shared workspace is ensured by providing access to documents stored in different repositories. CloudHQ functionality provides the ability to select any cloud storage being available from the library for consolidated backup of information from other cloud applications. CloudHQ has an online chat for communication with a technical support group in case of problems with a cloud manager.

The cloud manager platforms are the environments for creating information resources and management systems. They offer packages of tools that support the creation of such resources as well as facilities for their maintaining, user registration and management, the administration of information support processes and generation of reports about information resources consumption.

Therefore, there is a need to develop an approach that can combine essential characteristics of cloud manager platforms in order to develop evidence-based expert approach for choosing an effective platform for information support of virtual research teams. 


\section{Discussion of THE RESUlts of Cloud MANAGER RESEARCH USING THE BENCHMARKING METHOD AND THE EXPERT ESTIMATION METHOD}

To study, compare and identify a better cloud manager to support the scientific activity of virtual teams, we apply a number of methods in a consistent manner. Defining and comparing the functionality of cloud platforms is accomplished by benchmarking method.

Benchmarking is a methodology for comparative analysis to determine the standard obtained expertly for use as a benchmark, based on which an evaluation of any object can be formulated [13].

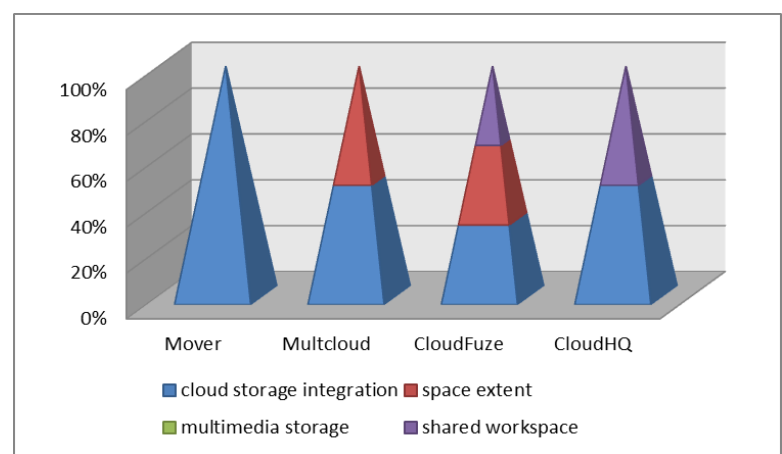

Fig.11. Comparison of functionality of cloud managers using the benchmarking method

The comparison showed that Multcloud and CloudFuze predominate among four cloud managers (Fig.11). It should be noted that Multcloud operates on a free-of-charge basis. The results of the benchmarking study will be verified by the hierarchy analysis method.

Table 1. Matrix of functionality of cloud managers

\begin{tabular}{|c|c|c|c|c|}
\hline & Mover & Multcloud & CloudFuze & CloudHQ \\
\hline $\begin{array}{c}\text { cloud } \\
\text { storage } \\
\text { integration }\end{array}$ & 1 & 1 & 1 & 1 \\
\hline space extent & 0 & 1 & 1 & 0 \\
\hline $\begin{array}{c}\text { multimedia } \\
\text { storage }\end{array}$ & 0 & 0 & 0 & 0 \\
\hline $\begin{array}{c}\text { shared } \\
\text { workspace }\end{array}$ & 0 & 0 & 1 & 1 \\
\hline
\end{tabular}

This platform should allow using tools to provide requirements for organization of effective work of virtual research teams. To choose the right platform we use the expert estimation method and the method of pairwise comparisons for hierarchy analysis developed by T. Saati $[14 ; 15 ; 16]$ and it is shown on Fig. 12.

We construct an appropriate hierarchy by a three-level structure for the application of the hierarchy analysis method. The upper level is a target according to which the decision is made; the second level is a set of criteria for the choice of alternative platforms for the information service of virtual research teams. These platforms form alternatives that create the lower level of the hierarchy. In this case the decision arrival is to choose one from the possible alternatives based on the construction of the priority vector. The priority is a real number which is assigned to each alternative. The alternative with the highest priority is an acceptable solution. The priority of an alternative is also called the weight of alternatives.

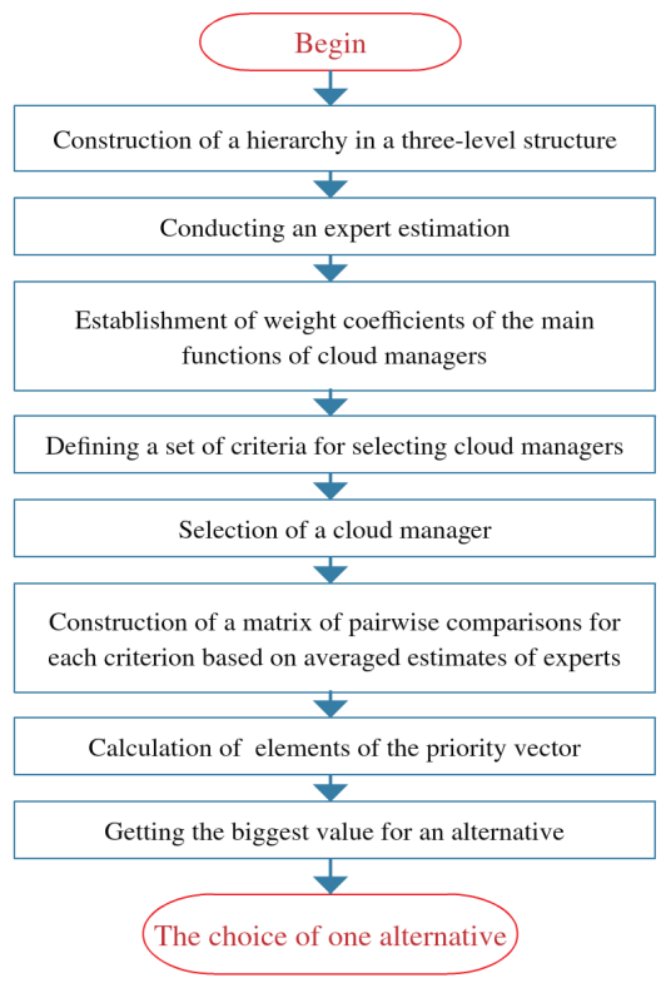

Fig.12. The algorithm for selecting the required platform by methods of expert estimates and pairwise comparisons for the hierarchy analysis

The appropriate tree has the form shown in Fig. 13. We understand the platforms for the information support as the alternatives, and criteria are based on the analysis of properties and possibilities of using the selected platforms. An important factor in the criteria formulation are the capabilities of adapting them to the information support of virtual research teams according to which the software will be chosen.

The aim is to select one of the alternatives based on the set of defined criteria. The choice of alternatives is performed by calculating the vector elements of priorities which are assigned to each alternative. The alternative with the highest value of such element is an acceptable decision.

In the hierarchy analysis method we use a scale of expert estimates or degrees of importance that are estimates for pairwise comparisons when the advantages of the first object on a second are evaluated.

The authors held the expert estimation procedure to determine the key features of the platforms. The experts used a scale from 1 to 9 evaluating the functions of tool sets of the cloud manager platforms. The general meaning of these estimates is shown in Table 1. 


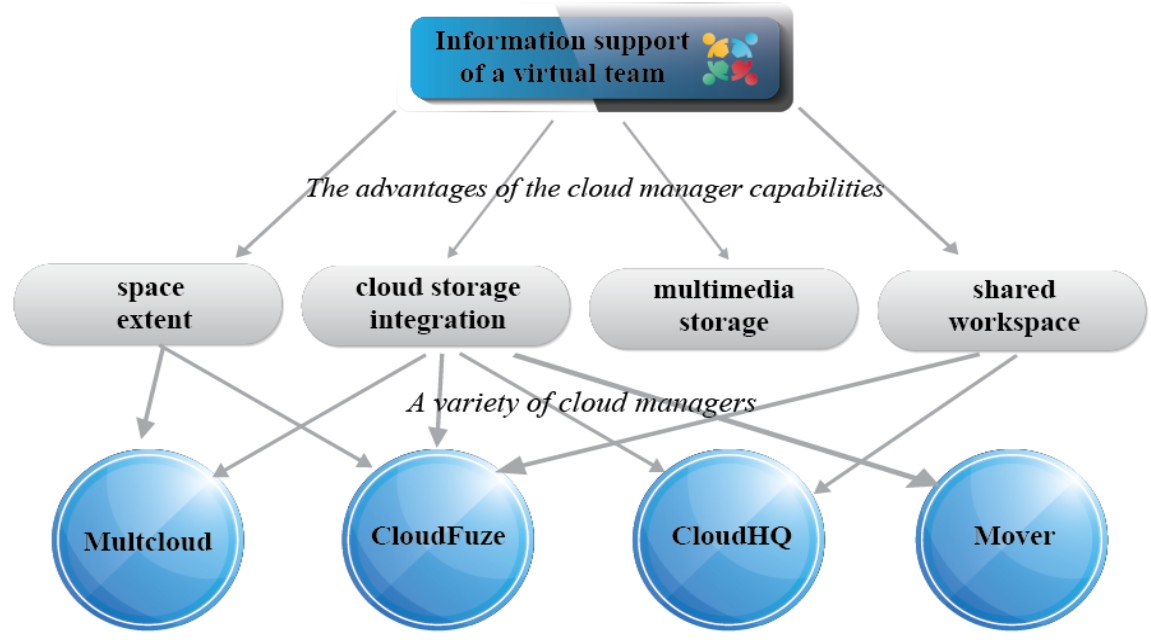

Fig.13. The general scheme of the hierarchy analysis method which is used for selecting distance learning platform

10 experts were involved in the assessment procedure. The weight coefficients received from experts for each function of the tool set of cloud manager platforms were averaged by formula [17]:

$$
\omega_{j}=\sum_{i=1}^{m a[} \beta_{i} \times i_{\max }^{-1}
$$

where $\omega_{j}$ is an averaging result, $\beta_{i}$ is a weight coefficient of the system function evaluation, $i_{\max }$ is a number of questioned experts.

It gave the opportunity to get the weight coefficient of functions of a tool set for electronic document systems, which is defined by the normalization [18] according to the formula:

$$
k_{i}=\frac{\omega_{j}}{100}
$$

where $\omega_{j}$ is a result of averaging obtained by the formula (1).

The weight coefficients of basic functions of a number of cloud management instrumental sets were made by the expert evaluation method and the averaging was done by formula (1). The free tool sets of cloud managers were selected for the research. We will form a set of criteria based on the analysis of the capability of the selected platforms for distance education. According to them the platform will be chosen by expert estimates, obtained by the hierarchy analysis method.

The main criteria were selected and the weights of alternatives were calculated for them:

1. The amount of space. It is the presence of own storage space in the cloud manager with the further possibility to increase it by consolidating cloud storage accounts.

2. The integration of cloud storages. It is the ability to integrate cloud storages, email applications, social networks in cloud manager environment and ensure their interoperability.
3. The multimedia storage. It is the possibility of the cloud manager to collect, store, exchange between cloud storages and playback of multimedia resources, directly in the cloud manager, as files of this type take a significant amount of memory.

4. The shared workspace. It is the possibility of collective work on projects directly in the cloud manager, providing access to the file directory or a file for all members of a virtual team.

Table 2. The determination of the degree of importance for the matrix of pairwise comparisons

\begin{tabular}{|c|c|c|}
\hline $\begin{array}{c}\text { Degree of } \\
\text { importance }\end{array}$ & Definition & Comment \\
\hline 1 & Equal importance & $\begin{array}{c}\text { Both objects make the } \\
\text { equal contribution to the } \\
\text { achievement of a goal }\end{array}$ \\
\hline 3 & $\begin{array}{c}\text { Experience and judgment } \\
\text { provide a slight advantage } \\
\text { to the first object over the } \\
\text { second }\end{array}$ \\
\hline 5 & $\begin{array}{c}\text { Substantial or } \\
\text { strong significance }\end{array}$ & $\begin{array}{c}\text { Experience and judgment } \\
\text { provide a strong advantage } \\
\text { the first object over the } \\
\text { second }\end{array}$ \\
\hline 9 & $\begin{array}{c}\text { Very strong and } \\
\text { evident } \\
\text { significance }\end{array}$ & $\begin{array}{c}\text { The advantage of the first } \\
\text { object over the second is } \\
\text { very strong. Its advantage } \\
\text { is almost obvious. }\end{array}$ \\
\hline $2,4,6,8$ & $\begin{array}{c}\text { Absolute } \\
\text { significance } \\
\text { between adjacent } \\
\text { scale values }\end{array}$ & $\begin{array}{c}\text { The evidence for the } \\
\text { advantages of the first } \\
\text { object is convincing in the } \\
\text { highest degree }\end{array}$ \\
\hline $\begin{array}{c}\text { Reciprocal } \\
\text { of listed } \\
\text { values }\end{array}$ & $\begin{array}{c}\text { Comparing object } \\
\text { A to object B, one } \\
\text { of these values is } \\
\text { received, and the } \\
\text { comparison result } \\
\text { of object B to } \\
\text { object A, is a } \\
\text { reciprocal }\end{array}$ & \multicolumn{2}{c|}{ compromise solutions } \\
\hline
\end{tabular}

The next step is to select a platform for information support of virtual research teams. The hierarchy analysis method is used for it. Using the average estimates of 
experts we will construct a matrix of pairwise comparisons for each criterion and calculate the numerical characteristics of these matrices: the largest eigenvalue, consistency index, and the index of the sequence of relationships. Each matrix consists of the average expert estimates regarding pairs of alternatives, which are the information providing platforms for virtual research teams.

The matrix of pairwise comparisons for selecting the alternative platforms by criterion "amount of space" is shown in the Table 3.
Table 3. The matrix of pairwise comparisons for selecting the alternatives by the criterion "amount of space"

\begin{tabular}{|c|c|c|c|c|}
\hline Alternatives & Multcloud & CloudFuze & CloudHQ & Mover \\
\hline \hline CloudFuze & 0,33 & 1,00 & 3,00 & 7,00 \\
\hline Mover & 0,11 & 0,14 & 0,33 & 1,00 \\
\hline CloudHQ & 0,20 & 0,33 & 1,00 & 3,00 \\
\hline Multcloud & 1,00 & 3,00 & 5,00 & 9,00 \\
\hline \hline Sum & $\mathbf{1 , 6 4}$ & $\mathbf{4 , 4 7}$ & $\mathbf{9 , 3 3}$ & $\mathbf{2 0 , 0 0}$ \\
\hline \hline
\end{tabular}

Table 4 . The alternative weights by the criterion "amount of space"

\begin{tabular}{|c|c|c|c|c|c|c|}
\hline Alternatives & Multcloud & CloudFuze & CloudHQ & Mover & Sum & $\begin{array}{c}\text { Alternative } \\
\text { weights }\end{array}$ \\
\hline \hline Multcloud & 0.479 & 0.606 & 0.395 & 0.375 & 2.604 & 0.4340 \\
\hline CloudFuze & 0.160 & 0.202 & 0.237 & 0.292 & 1.557 & 0.2594 \\
\hline CloudHQ & 0.096 & 0.067 & 0.079 & 0.125 & 0.534 & 0.0889 \\
\hline Mover & 0.053 & 0.029 & 0.026 & 0.042 & 0.233 & 0.0389 \\
\hline \hline Sum & $\mathbf{0 , 7 9}$ & $\mathbf{1 . 5 1}$ & $\mathbf{0 . 7 4}$ & $\mathbf{0 . 8 3}$ & $\mathbf{4 . 9 3}$ & $\mathbf{0 . 8 2}$ \\
\hline
\end{tabular}

The results of calculation of the estimates of alternative weights according to the criterion "amount of space" are shown in the Table 4 . The calculations are made according to the method 3 [12], where the elements of the columns in the Table 4 are obtained by the normalization of appropriate elements in the columns in the Table 3.

Now we will calculate the vector of priorities as the main assessment of eigenvector of the matrix of pairwise comparisons. The elements of this vector are the alternative weights, calculated as the algebraic sum of the elements of the appropriate row in the Table 4, divided into the total number of alternatives, i.e. the amount of line items in the Table 3.

Thus, due to the criterion "amount of space" the best alternative is a free Multcloud platform, because it has the highest weight value -0.4340 .

For the matrix of pairwise comparisons based on the criterion "amount of space", the following parameters are calculated:

- the estimation of the largest eigenvalue, which is calculated according to the formula: $\lambda_{\max }=\sum_{i=1}^{n} w_{i} s_{i}$, where $w_{i}$ - alternative weight with a number $i, s_{i}$-sum of the elements in column with a number $i$ of the matrix of pairwise comparisons, $n$-number of alternatives;

- the index of consistency $C I=\frac{\lambda_{\max }-n}{n-1}$;

- the index of the sequence of ratios $C R=\frac{C I}{R I}$.

Here and further $R I=1,24$ - random index for $n=4$, with the same value for all further calculations of the alternative weights.

After calculating the matrix of pairwise comparisons, built by the "amount of space" criterion, parameters get the following values:

$$
\begin{aligned}
& \lambda_{\max }=0,434 * 1,64+0,2594 * 4,47+0,0889 * 9,33+ \\
& +0,0389 * 20=3,4787
\end{aligned}
$$

the index of consistency

$$
C I=\frac{\lambda_{\max }-n}{n-1}=\frac{3,4787-4}{4-1}=-0,1737
$$

the index of the sequence of relations

$$
C R=\frac{C I}{R I}=\frac{-0,1323}{1,24}=-0,14
$$

As $C R=-0,14<10 \%$, the matrix of pairwise comparisons for the criterion "amount of space" is considered to be consistent.

\section{CONCLUSION}

Thus, our calculations showed that the best toolkit for information support of virtual research teams is Multcloud manager, because it has extensive free of charge disk space, achieved with consolidating cloud storages.

Among file managers, covering a wide range of cloud storages, it should be noted: Multcloud and CloudHQ. Platform CloudHQ gives way before Multcloud. Multcloud can integrate the largest number of cloud services. The extension of the primary disk space of file managers is achieved due to the integration of cloud storages.

CloudFuze stands out as the only cloud manager that ensures the common work with documents. However, the service is paid. The opportunity of free testing of the 
service is given.

\section{REFERENCES}

[1] Camarinha-Matos L. M., Silveri I., Afsarmanesh H., Oliveira A. I. "Towards a framework for creation of dynamic virtual organizations", Collaborative Networks and Their Breeding Environments, IFIP TC5 WG 5.5 Sixth IFIP Working Conference on Virtual Enterprises, September 2005, pp. 69-81.

[2] Chesbrough H. W., Teece D. J. "When is virtual virtuous? Integrated alliances virtual organizing for innovation", Harvard Business Review, 1996, pp. 65-76.

[3] Petersen S. A. "The role of enterprise modeling in virtual enterprises", Collaborative Networks and Their Breeding Environments, IFIP TC5 WG 5.5 Sixth IFIP Working Conference on Virtual Enterprises, 2005, pp. 109-117.

[4] Zhurovskii M., Petrenko A. "E-science towards a semantic grid. Part 1: Combining WEB and GRID technologies", System research and information technologies, 2010, no 1, pp. 26-38.

[5] Sangeeta N. Dhamdhere "Cloud computing and virtualization technologies in libraries", 2013, 385 p.

[6] Nandkishor Gosavi, Seetal S. Shinde, Bhagyashree Dhakulkar "Use of cloud computing in library and information science field", International Journal of Digital Library Services, 2012, vol. 2, iss. 3, pp. 51-60.

[7] Suresh Kumar V., Aramudhan. M. "Trust based resource selection in cloud computing using hybrid algorithm", International Journal of Intelligent Systems and Applications (IJISA), 2015, vol. 7, no 8, pp. 59-64.

[8] Arman A. "A risk-aware application scheduling model in cloud computing scenarios", International Journal of Intelligent Systems and Applications (IJISA), 2016, vol. 8, no 10 , pp. 11-20.

[9] Sasikala P. "Cloud computing: present status and future implications", International Journal Cloud Computing, 2011, vol. 1 , iss. 1, pp. 23-36.

[10] Rzheuskiy A., Kunanets N., Kut V. "Cloud managers - an innovative approach to the management of the library information resources", Econtechmod, 2017, vol. 6, no 2, pp. $51-58$.

[11] Veretennikova N., Pasichnyk V., Kunanets N., Gats B. "E-Science: new paradigms, system integration and scientific research organization", Computer Science and Information Technologies: Proceedings of the Xth International Scientific and technical Conference CSIT, 201, Lviv: Lviv Polytechnic Publishing House, pp. 76-81.

[12] Bultje R., Wijk J. "Taxonomy of virtual organizations, based on definitions, characteristics and typology", Vonet. Newsletter, 1998, vol. 2, no 3, pp. 7-20.

[13] Dalalah D., Al-Rawabdeh W. "Benchmarking the utility theory: a data envelopment approach", Benchmarking: An International Journal, 2017, vol. 24 iss. 2, pp. 318-340.

[14] Saati T. "Decision-making. Method for analyzing hierarchies", Moscow, 1993, 278 p.

[15] Pavlov O., Ivanova G., Kut V., Shtankevych O. "Mathematical models of optimization for finding objects weights in decision support methods", Proceedings of the VIII International conference Intelligent information analysis, May 2008. - 608 p. (in Ukrainian)

[16] Pavlov O., Ivanova G., Kut V., Shtankevych O. "Mathematical models of optimization for finding objects weights in decision support methods", Proceedings of the XI Ukrainian student scientific conference on applied mathematics and computer science, April 2008, pp. 68-67. (in Ukrainian)
[17] The market of document management systems and records management (end of 2004). Available at: http://bit.ly/2rjBywo.

[18] Dmytro Peleshko, Taras Rak, Ivan Izonin "Image Superresolution via Divergence Matrix and Automatic Detection of Crossover", International Journal of Intelligent Systems and Applications (IJISA), Vol.8, No.12 pp.1-8, 2016. DOI: 10.5815/ijisa.2016.12.01

[19] F. Stowell and S. Cooray, "Virtual teams and conflicts: The role of Action Research", 9th International Conference on Human System Interactions (HSI), Portsmouth, 2016, pp. 164-171. doi: 10.1109/HSI.2016.7529626

\section{Authors' Profiles}

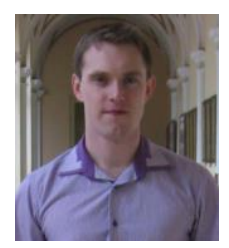

Rzheuskiy Antoniy has $\mathrm{PhD}$ of Social Communication at the Department of Information systems and networks at Lviv Polytechnic National University (Ukraine).

His main research interests are in the area of information science, social communication science, and scholarly

communication.

$\mathrm{He}$ is also interested in e-learning, cloud technologies, elibraries, information support of scientific research.

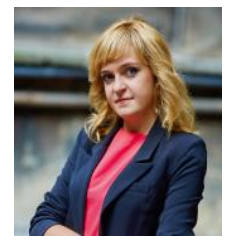

Veretennikova Nataliia is $\mathrm{PhD}$ of Social Communication, the assistant of the Department of Information Systems and Networks and the Department of Applied Linguistics.

She has been working at Lviv Polytechnic National University since 2015.

She conducts research in the field of e-science, linguistic and information support of virtual creative teams.

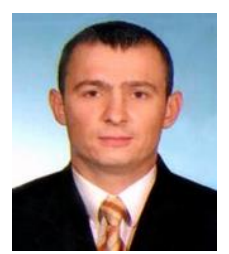

Kut Vasyl is PhD of Technical Sciences, the head of the Department of Information Technologies and Analytics of the Carpathian University named after Augustine Voloshin.

In 2013 he defended the thesis.

His scientific interests include studying information technology for inclusive education, decision support systems, and information analysis and business analytics.

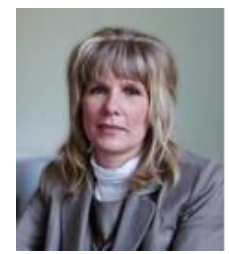

Kunanets Nataliia is Dr. of Science in the area of Social Communication, Senior Fellow, Professor of the Department of Information Systems and Networks, Deputy Head of the department at Lviv Polytechnic National University.

She started her work in 1981 at Lviv Stefanyk National Science Library. Since 2009 she has been working at Lviv Polytechnic National University.

She conducts research on problems of social and communicative technology in projects "Smart City", information support of scientific research carrying out on the platform of e-science and consolidation of information resources. 
How to cite this paper: Antoniy Rzheuskiy, Nataliia Veretennikova, Nataliia Kunanets, Vasyl Kut, "The Information Support of Virtual Research Teams by Means of Cloud Managers", International Journal of Intelligent Systems and Applications(IJISA), Vol.10, No.2, pp.37-46, 2018. DOI: 10.5815/ijisa.2018.02.04 